\title{
DNA-Cationic Surfactant Interactions Are Different for Double- and Single-Stranded DNA
}

\author{
Mónica Rosa, ${ }^{\dagger, \ddagger}$ Rita Dias, ${ }^{*,+, \ddagger}$ Maria da Graça Miguel, ${ }^{\dagger}$ and Björn Lindman \\ Chemistry Department, Coimbra University, 3004-535 Coimbra, Portugal, and Physical Chemistry 1, Lund \\ University, P.O. Box 124, 22100 Lund, Sweden
}

Received February 25, 2005

\begin{abstract}
The stability of DNA in solution and the phase behavior in mixtures with dodecyltrimethylammonium bromide (DTAB) were investigated. By means of circular dichroism, UV absorption, and differential scanning calorimetry, we found that for dilute solutions of DNA with no addition of salt the DNA molecules are in the single-stranded conformation, whereas the addition of a small amount of $\mathrm{NaBr}, 1 \mathrm{mM}$, is sufficient to stabilize the DNA double-helix. Furthermore, at higher DNA concentrations, native DNA becomes the most stable structure, which is due to a self-screening effect. By phase diagram determinations of the DNAsurfactant system, we found that the effect of salt on phase behavior mainly relates to a difference in interaction of the amphiphile between single-stranded DNA (ssDNA) and double-stranded DNA (dsDNA). The difference in association between ss and dsDNA with surfactants of different chain lengths can be interpreted in terms of an interplay between hydrophobic and electrostatic interactions, the latter being influenced by polymer flexibility. In this way, a nonmonotonic variation can be rationalized. A crossing of the phase separation lines with DNA concentration can be rationalized in terms of a change in relative stability of ss and dsDNA. The fact that ssDNA phase separates earlier than dsDNA in association with DTAB, may serve as a basis for a method of easily separating dsDNA from ssDNA by the addition of surfactant; this is verified as monitored by circular dichroism measurements.
\end{abstract}

\section{Introduction}

During the initial excitement of cracking the genetic code, it was tempting to set aside the idea that the packing of DNA in the cell relates to gene expression. Now that the controlled expression of genes is of primary interest, the work on DNA compaction and packaging in living cells and its relationship with the transcription machinery is an important and relevant issue that is far from understood. ${ }^{1}$ It is believed that histones, spherical positively charged proteins, are responsible for DNA packaging in cells. ${ }^{1-3}$ The compaction of DNA, together with the reduction of its charge, is believed to facilitate the uptake of nucleic acids through the cellular membrane. ${ }^{4-8}$ Since the strong binding of cationic surfactants to DNA induces these two effects, it is not surprising that the complexation with cationic lipids is one strategy for delivery of DNA to cells.

Quaternary ammonium surfactants, despite their known cytotoxicity, ${ }^{9}$ have already been used, in small amounts, to charge neutral liposomes, thereby improving their transfection efficiency; they have the advantage of lower cost when compared with other synthetic lipids. ${ }^{9,10}$

With this work, we try to gain additional insight concerning the interactions between DNA and cationic surfactants and how they are influenced by the DNA conformation and stability in solution; the surfactant chosen in this study was dodecyltrimethylammonium bromide (DTAB).

\footnotetext{
* Corresponding author. E-mail: Rita.Dias@fkem1.lu.se.

Coimbra University.

$\doteqdot$ Lund University.
}

The B-DNA secondary structure is the most stable one under physiological conditions. However, certain changes in solution conditions, such as for instance temperature, induce a loss of its secondary structure, and DNA molecules undergo melting or denaturation. These terms represent the mechanism where a double-stranded DNA (dsDNA) falls apart and forms two single strands (ssDNA). This mechanism has been followed by techniques such as UV/vis spectroscopy and differential scanning calorimery (DSC) (ref 11, and references within). In such studies, denaturation was shown to be dependent not only on the temperature but also on the DNA base composition, the concentration of salt, the concentration of DNA, $\mathrm{pH}$, and the absorption of $\mathrm{CO}_{2}$ from air in the solution. ${ }^{12-14}$ In our studies, we did not consider this $\mathrm{CO}_{2}$ dependency. Also, we did not use buffer, since we were interested in having a more simple system that would serve as a model for better understanding of the interactions involved. Under conditions of full ionization of DNA, where this work was performed, $\mathrm{pH}$ has no effect.

Regarding the DNA-cationic surfactant system, its strong associative behavior has been documented in some detail and is related to some applications, like DNA extraction and purification using quaternary ammonium surfactants ${ }^{15}$ and the precipitation and counting of small quantities of DNA. ${ }^{16}$ The cetyltrimethylammonium bromide (CTAB) - DNA precipitation method is still in use, with more or less advanced modifications. ${ }^{17-20}$ In previous work, precipitation maps of DNA and cationic surfactants of various chain length were introduced. ${ }^{21} \mathrm{~A}$ marked and nontrivial difference was found 
in the precipitation behavior in the absence and presence of salt, especially for short-chained surfactants.

In this work, we started by studying the DNA stability in solution by varying the temperature and the salt concentration. Then we performed studies on the precipitation behavior of DNA-DTAB in more detail by looking at the salt concentration and temperature dependences under the same conditions. We found that the difference in the phase behavior of the systems relates to a difference in interaction of the amphiphile with dsDNA and ssDNA, respectively. This brings us to the possibility of easily separating dsDNA from ssDNA by simple addition of surfactant, which is demonstrated to be possible as monitored by circular dichroism (CD) measurements.

\section{Experimental Section}

Materials. dsDNA type XIV from herring testes, in the salt form, was purchased from Sigma and used as received. Its molecular weight was determined by gel electrophoresis and DNA was found to be polydisperse, with a range between 400 and 1000 base pairs, bp, and a center of distribution at ca. $700 \mathrm{bp}$. The DNA concentrations were determined spectrophotometrically considering that for an absorbance of 1 , at $260 \mathrm{~nm}$, a solution of dsDNA has a concentration of $50 \mu \mathrm{g} / \mathrm{mL}$ and a solution of ssDNA has a concentration of $40 \mu \mathrm{g} / \mathrm{mL} .^{22}$ All DNA concentrations are presented in $\mathrm{M}$ per phosphate group, i.e., $\mathrm{M}$ per negative charge. The ratios in absorbance at 260 and $280 \mathrm{~nm}$ of the stock solutions were found to be between 1.8 and 1.9, which suggested the absence of proteins. ${ }^{23}$ Dodecyltrimethylammonium bromide (DTAB) and tetradecyltrimethylammonium bromide (TTAB) were obtained from Sigma, and used without further purification. All solutions were prepared with Millipore water.

Sample Preparation. dsDNA stock solutions were prepared at different $\mathrm{NaBr}$ concentrations and diluted to the wanted concentration prior to the measurements. ssDNA stock solutions were prepared by thermal denaturation of dsDNA stock solution at $75{ }^{\circ} \mathrm{C}$ for $15 \mathrm{~min}$ and then immediately dipping into ice for fast cooling, to prevent renaturation. Dilution to the wanted concentration was performed prior to thermal denaturation. DNA solutions were kept at $\mathrm{pH} 7-8$; some drops of a diluted solution of $\mathrm{NaOH}$ were added when needed. For the differential scanning calorimetry (DSC) experiments, all samples were degassed.

For the purposes of the dissolution of the DTA:DNA complex with simple salt, we started by making a neutral complex, 1:1 with respect to charge of DTAB and DNA. For that, two solutions with the same concentration with respect to charge of DTAB and DNA, respectively, were mixed at room temperature. Mixing of the two solutions was performed while stirring. The precipitate was filtered and washed several times with Millipore water, in order to eliminate all counterions, and then dried in the freeze-dryer for 3 days. The complex was weighed for each sample and $\mathrm{NaBr}$ solutions of different concentrations were added to screw-capped glass tubes reaching the final volume of $0.5 \mathrm{~mL}$. Samples were kept on a shaker to equilibrate for several weeks.
Samples for separation purposes were prepared by mixing dsDNA stock solutions containing $10 \mathrm{mM}$ NaBr with ssDNA and DTAB stock solutions. Each sample was chosen by analysis of the phase diagram of DNA-DTAB at different salt concentrations, shown in Figure 5.

Precipitation Map Determination. For the precipitation map determination, several samples were prepared by volume, adding the desired amount of surfactant and DNA stock solutions, and water, in screw-capped glass tubes with the total of $1 \mathrm{~mL}$. Addition of each component was performed while stirring. Samples were kept in the magnetic stirrer for $4 \mathrm{~h}$ and left to equilibrate for at least $48 \mathrm{~h}$. Turbidity measurements of the samples were performed on a PerkinElmer UV/vis Lambda 14 spectrometer at two different wavelengths, 350 and $400 \mathrm{~nm}$. All samples were kept at $25{ }^{\circ} \mathrm{C}$.

Circular Dichroism. CD measurements were performed with a model Jasco-720 spectropolarimeter. Spectra were acquired in a $0.5 \mathrm{~cm}$ path length quartz cuvette at $25^{\circ} \mathrm{C}$, with the temperature being maintained with a Peltier device. Three scans were averaged per spectrum, operating from 220 to $300 \mathrm{~nm}$ at a scan speed of $10 \mathrm{~nm} / \mathrm{min}$ and a bandwidth of $1 \mathrm{~nm}$. Measurements were performed under a constant nitrogen flow, to purge the ozone generated by the light source of the instrument. All results were normalized with concentration.

Differential Scanning Calorimetry. A high-sensitive differential scanning calorimeter MicroCal MC.2 (Microcal Inc., Northampton, MA), equipped with two total-fill cells of $1.2 \mathrm{~mL}$, one for the reference and another for the solution to be studied, was used. The solutions were degassed using a Nueva II stirrer (Thermolyne) before being transferred to the cells using a Hamilton syringe. The scan rate used was of $60{ }^{\circ} \mathrm{C} / \mathrm{h}$. A reference thermogram was also measured for both cells filled with the reference solution. Computer analysis of the DSC data was performed using Origin Scientific plotting software, version 5. Data was analyzed after subtraction of the baseline obtained by scanning with the corresponding reference solutions in both sample and reference cell. Repeated scans revealed good reproducibility in both the transition maxima and their thermodynamic parameters.

Ultraviolet Melting Spectra. Thermal denaturation corresponds to the transition of dsDNA to ssDNA; the temperature at which UV absorbance reached half of its final value is denoted the melting temperature, $T_{\mathrm{m}}$.

UV melting spectra were measured on a Cary 300 Bio UV-visible spectrometer (Varian), at the wavelength of $260 \mathrm{~nm}$, using a $0.5 \mathrm{~cm}$ path length quartz cell. A Peltier device was used in order to control temperature.

For the UV melting spectra of DNA $(0.1 \mathrm{mM})$ in the presence of different cationic surfactants, we used $1.5 \mathrm{mM}$ DTAB and for TTAB $0.15 \mathrm{mM}$. These values of concentration were chosen for being below the precipitation line of these systems. ${ }^{21}$

\section{Results and Discussion}

DNA Stability in Solution. As mentioned above, denaturation of DNA molecules is dependent on several param- 


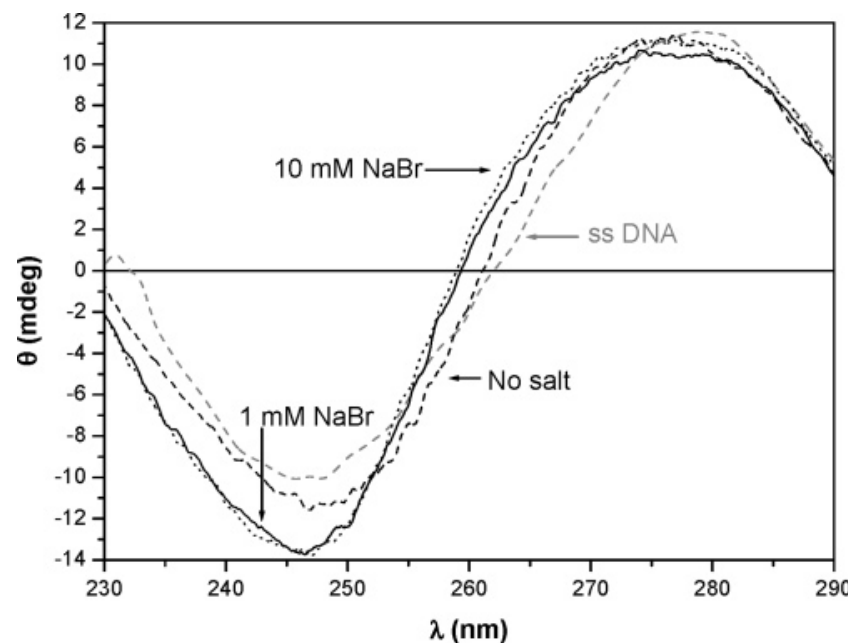

Figure 1. Circular dichroism of DNA $(0.1 \mathrm{mM})$ at different concentrations of $\mathrm{NaBr}$. Curves for $\mathrm{NaBr}$ concentrations of $10.0 \mathrm{mM}$ (dotted line) and $1.0 \mathrm{mM}$ (solid line) closely overlap and correspond to the native B-form of DNA. The dashed lines correspond to single-stranded DNA, prepared in the absence of salt (black line) and by heat denaturation (gray line). $T=25^{\circ} \mathrm{C}$.

eters. In the literature, some of these dependencies have been reported and related according to the following equation, $T_{\mathrm{m}}=16.6 \log C_{\mathrm{s}}+41 \chi_{\mathrm{gc}}+81.5,{ }^{13}$ where $C_{\mathrm{s}}$ is the total salt concentration (in $\mathrm{M}$ ) and $\chi_{\mathrm{gc}}$ is the mole fraction of $\mathrm{G}-\mathrm{C}$ in the DNA. Later, Korolev et al. presented further dependencies, the concentration of DNA itself and the absorption of $\mathrm{CO}_{2}$ from air, the last being considered to cause protonation of DNA bases. ${ }^{12} \mathrm{We}$ did not consider this $\mathrm{CO}_{2}$ dependency in our studies and performed our experiments in the absence of buffer, focusing on the effects of temperature and salt concentration in solution. The $\mathrm{pH}$ was kept constant at values between 7 and 8 .

The techniques chosen to monitor DNA denaturation were $\mathrm{CD}, \mathrm{UV} /$ vis spectroscopy, and DSC.

$\mathrm{CD}$ has been adopted for the determination of the conformation of proteins and nucleic acids in solution for over 30 years. The application of this technique to study DNA conformations has stemmed from the sensitivity and ease of measurements, the nondestructive nature, the fact that conformations can be studied in solution, and the requirement of only small amounts of material. ${ }^{24} \mathrm{We}$ used it to establish the DNA conformation at room-temperature varying the salt concentration.

In Figure 1, the results of the $\mathrm{CD}$ measurements are presented. We can see that at the studied temperature, $25^{\circ} \mathrm{C}$, the DNA solutions with 1.0 and $10.0 \mathrm{mM}$ of $\mathrm{NaBr}$ present a $\mathrm{CD}$ spectrum with the characteristic features of double-stranded B-form DNA, consisting of a positive band around $275 \mathrm{~nm}$, a negative signal, with approximately the same intensity, at $245 \mathrm{~nm}$, and a maximum in absorbance, at the crossover point, near $258 \mathrm{~nm} \cdot{ }^{24-29}$ For the DNA sample with no addition of salt, we observe a red shift of the wavelength crossover from 258 to $261 \mathrm{~nm}$ as well as a decrease in the amplitude of the negative $\mathrm{CD}$ band, features that usually indicate denaturation, or melting. ${ }^{24}$ The decrease in the amplitude of the negative CD band has been reported to be related to a decrease in helicity of DNA. ${ }^{30}$ The $\mathrm{CD}$ spectrum of a heat denaturated DNA sample is included in

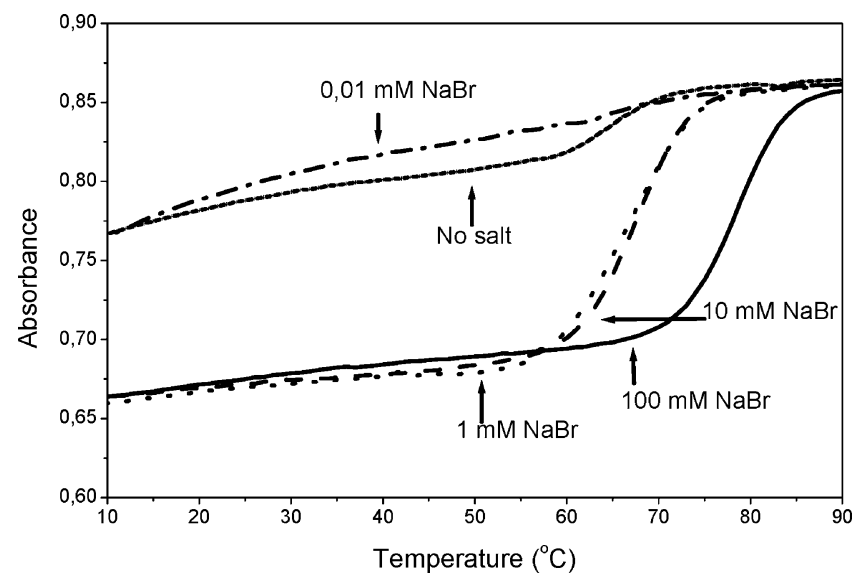

Figure 2. Melting curves of $0.1 \mathrm{mM}$ DNA at different salt concentrations: $[\mathrm{NaBr}]=100.0 \mathrm{mM}$ (solid line), $10.0 \mathrm{mM}$ (dashed line), $1.0 \mathrm{mM}$ (dotted line), $0.01 \mathrm{mM}$ (dash dotted line), and no salt (crosses line).

the figure. As can be seen, this curve is very similar to the one prepared in the absence of salt, which further confirms its melted state.

We can conclude then that, for solutions with a low DNA concentration, $0.1 \mathrm{mM}$ approximately, the addition of $1 \mathrm{mM}$ of salt is sufficient to stabilize the DNA secondary structure in its native B-form conformation. When using no salt at all for this temperature, $25^{\circ} \mathrm{C}$, and DNA concentration, the double-helix molecules undergo denaturation to singlestranded DNA molecules.

Native DNA shows a hyperchromic shift or an absorption increase of about $40 \%$ at $260 \mathrm{~nm}$, by UV/vis light absorption, as it denaturates; in this way, the melting transition can be obtained by monitoring the UV light absorption at that wavelength, while the temperature of the solution is gradually increased. The resulting spectra are typically called melting curves and, as mentioned previously, give the melting temperature of the system, as the midpoint of the transition.

In Figure 2 are exhibited the melting curves for DNA solutions, of $0.1 \mathrm{mM}$ in phosphate charges, for different concentrations of salt. We can see, as observed with CD at room temperature, that as little as $1.0 \mathrm{mM}$ of salt is sufficient to stabilize the double-helix DNA molecules. Also, we see no marked difference between these samples and the ones with $10.0 \mathrm{mM}$ of $\mathrm{NaBr}$; the inflection point of the curves, i.e., the melting temperatures, are about 66 and $67{ }^{\circ} \mathrm{C}$, respectively. For the sample with the highest content of salt $(100 \mathrm{mM})$, the melting temperature increases further, $78^{\circ} \mathrm{C}$. The melting curve for the samples with no salt presents a slightly sigmoidal shape indicating that the molecules undergo some melting. There is some evidence of ordered structures in single stranded DNA molecules believed to be due to base stacking $;{ }^{31}$ it is then possible that these base stack regions undergo melting with an increase of temperature.

DSC is another technique that can be used for the determination of melting temperatures, having the advantage that solutions with higher concentrations can be monitored. We started by performing DSC studies on dilute DNA solutions, $0.5 \mathrm{mM}$, and varying $\mathrm{NaBr}$ concentrations. For this technique, the concentration of DNA used was higher than for the previous studies, since we found it to be difficult 


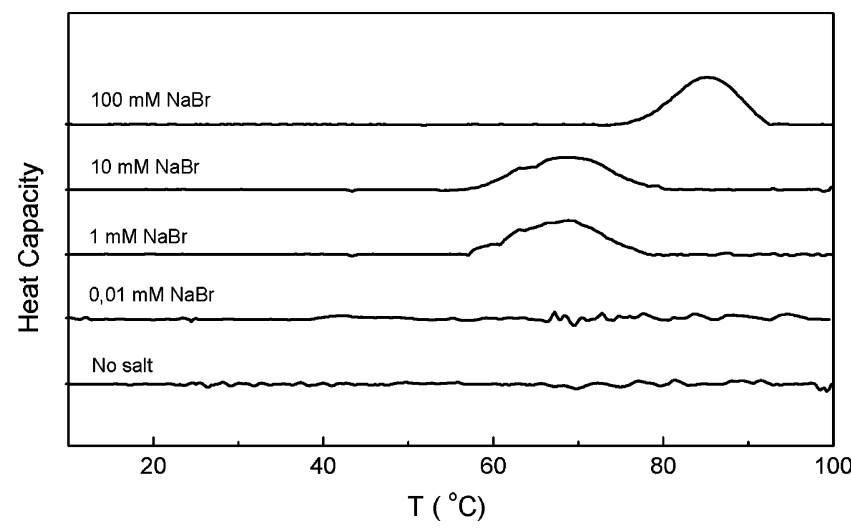

Figure 3. Differential scanning calorimetry traces for $0.5 \mathrm{mM}$ DNA solutions, at different concentrations of salt (as indicated).

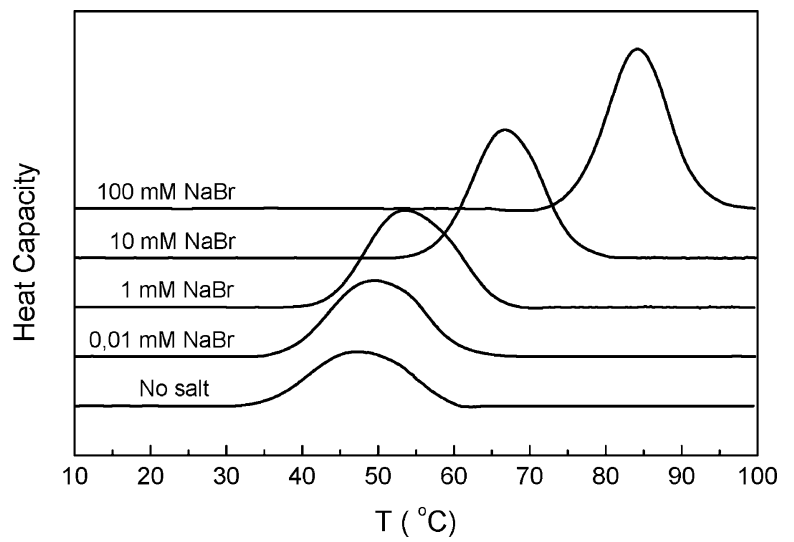

Figure 4. Differential scanning calorimetry curves for $6.0 \mathrm{mM}$ DNA solutions, at different concentrations of salt (as indicated).

to obtain reproducible results for DNA concentrations around $0.1 \mathrm{mM}$. However, as can be seen in Figure 3, the results were quite similar to the ones obtained from the melting curves determined by UV/vis absorption. No transitions were obtained for the DNA solutions with no or little $(0.01 \mathrm{mM})$ salt. Again, for the samples with 1.0 and $10.0 \mathrm{mM}$ of salt the curves are identical and the melting occurred at $68.7^{\circ} \mathrm{C}$ for both. For $100.0 \mathrm{mM}$ of salt, the transition was observed for a higher temperature, $82.5^{\circ} \mathrm{C}$.

The same studies were performed for more concentrated solutions of DNA, of about $6 \mathrm{mM}$. In this case, we can see (Figure 4) that even for the salt-free DNA solution there is a peak corresponding to the DNA melting, indicating that the presence of the DNA counterions is sufficient to stabilize the double-helix conformation at room temperature and clearly indicating a self-screening effect. DNA, like other polyelectrolytes, dissolves in solution due to the release of its counterions. However, part of them remain associated as predicted by Manning-Oosawa counterion condensation theory $^{32}$ and Poisson-Boltzmann ${ }^{33}$ calculations. When the concentration of DNA is increased, the amount of free counterions in solution increases too, which contributes to the increase of the ionic strength. This way, the mechanism of stabilization of dsDNA by increasing its concentration can be seen as a simple addition of salt. Inman et al. found similar results by measuring the specific conductivity against DNA concentration in the absence of added salt. ${ }^{34}$ They found a definite discontinuity at $0.3-0.2 \mathrm{mM}$ DNA which they attribute to a denaturation process, where the sodium counterions play an essential role in stabilizing the double helix; this phenomenon was named by them as the shielding action. ${ }^{34}$ In our work, this discontinuity occurs in the concentration range of $0.56-0.5 \mathrm{mM}$ DNA (results not shown). We start then to detect the presence of dsDNA molecules for a concentration of $0.56 \mathrm{mM}$.

In Figure 4, we can also observe that with an increase of salt one can stabilize the dsDNA molecules to higher temperatures; also the transition peak becomes sharper and more intense, indicating a more cooperative transition. Hence, in this case, we do observe a more straightforward correlation between the denaturation temperature and the amount of salt.

DNA-Cationic Surfactant Phase Behavior. As mentioned, DNA melting is dependent on several factors, ${ }^{12,13}$ the focus of our studies being on the salt and DNA concentrations. As shown above, for solutions with low DNA concentration and no salt, the molecule is in its denaturated state, whereas as low addition as $1 \mathrm{mM}$ of $\mathrm{NaBr}$ is sufficient to keep the DNA molecules in their native double-helix state.

We performed precipitation studies of DNA solutions by the addition of DTAB in the absence and presence (1.0 and $100.0 \mathrm{mM}$ ) of $\mathrm{NaBr}$. The results are presented in Figure 5a. We can see that, for the DNA solutions in the absence of salt, a lower amount of surfactant is needed to induce phase separation than for the dsDNA solutions. It can be argued that this behavior is a general feature for polyelectrolyteoppositely charged surfactant systems. It is commonly accepted that the critical aggregation concentration (CAC) of polyelectrolyte-oppositely charged surfactant systems increases on addition of salt. ${ }^{35}$ This is due to a weakened interaction between the polymer and surfactant induced by the stabilization of (free) micelles and a screening of the electrostatic interactions. This delays the precipitation of the system and decreases the two-phase region. However, in our study, we observe a crossing of the two precipitation lines, which is novel and not expected from earlier work; moreover, there are no perceptible differences in the phase separation of the system between 1.0 or $100.0 \mathrm{mM} \mathrm{NaBr}$, suggesting that the system is not very sensitive to the salt concentration changes within this concentration range.

Our conclusion is that the differences in behavior arise from the fact that we have different DNA conformations; the crossing of the precipitation lines gives further evidence of this fact. For low DNA concentrations, the ssDNA molecules are more stable than the corresponding double stranded ones; thus, dsDNA precipitates more readily with the cationic surfactant. In the same way, for higher DNA concentrations, the ssDNA is less stable and precipitates for lower surfactant concentrations.

To test our conclusion, we studied the temperature dependence of the same system. The temperatures used were 4,25 , and $50^{\circ} \mathrm{C}$ with a fixed concentration of salt, $10^{-5} \mathrm{M}$. Under these conditions, we have the dsDNA conformation at $4{ }^{\circ} \mathrm{C}$ and the single stranded conformation for the two other temperatures.

From the precipitation diagram presented in Figure 5b, we can see the same features as in Figure 5a. For the two higher temperatures, less surfactant is required to induce the 
a)

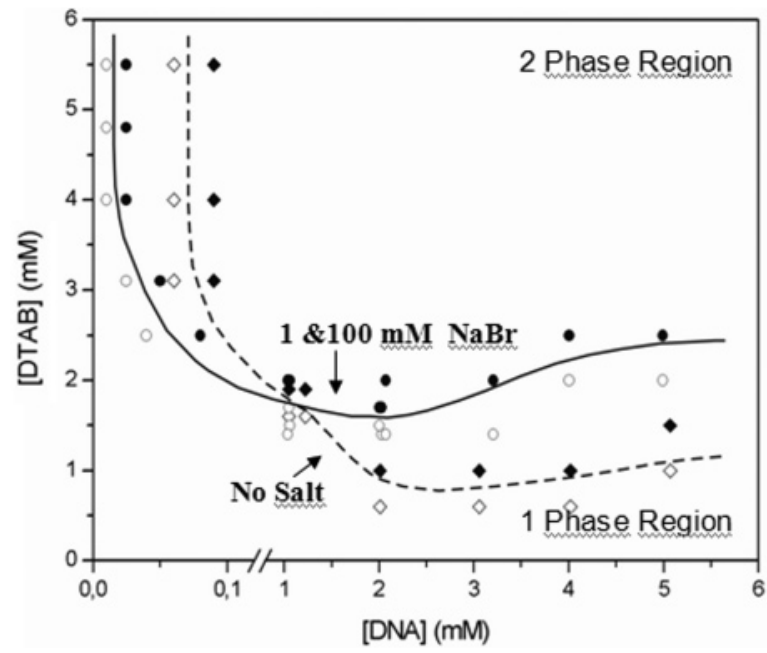

b)

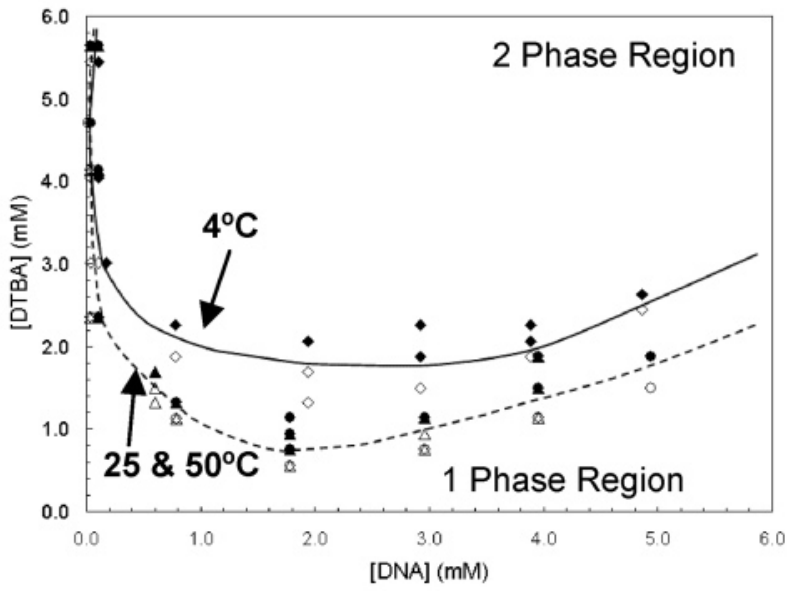

c)

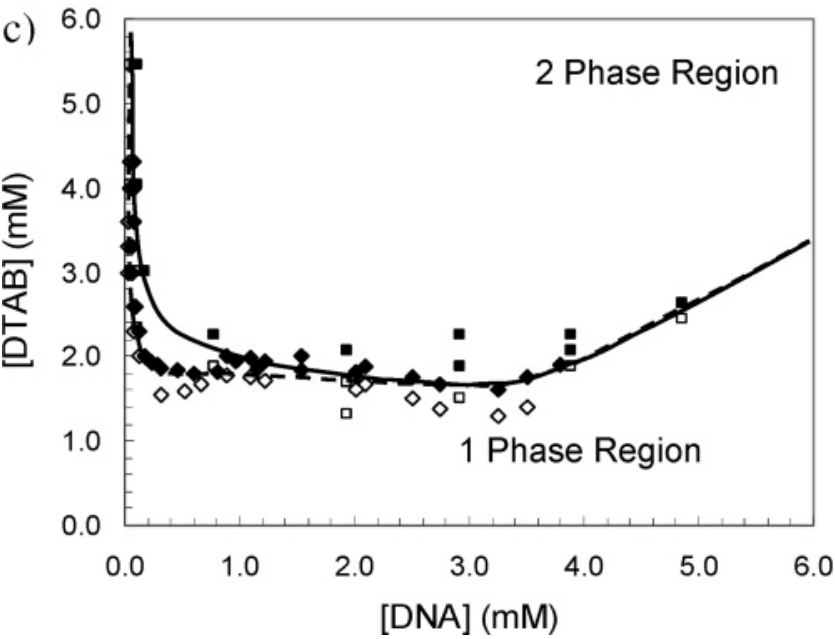

Figure 5. Precipitation maps for the system DNA-DTAB-water at different conditions. (a) System containing 1 and $100 \mathrm{mM} \mathrm{NaBr}$ (circles) and no salt (diamonds); all at $25^{\circ} \mathrm{C}$. (b) Samples kept at $4{ }^{\circ} \mathrm{C}$ (diamonds), $25^{\circ} \mathrm{C}$ (triangles) and $50{ }^{\circ} \mathrm{C}$ (circles); containing $10^{-5} \mathrm{M}$ of $\mathrm{NaBr}$. (c) Comparison between the systems with $100 \mathrm{mM}$ of salt at $25^{\circ} \mathrm{C}$ and the samples prepared at $4{ }^{\circ} \mathrm{C}\left(10^{-5} \mathrm{M}\right.$ of $\left.\mathrm{NaBr}\right)$; i.e., when DNA is in its native form. Open symbols correspond to clear one-phase solutions and filled symbols to two-phase samples. Dashed and solid lines were added with the purpose of guiding the eye and easily detect the phase borders for each system.

phase separation of the DNA-DTA complexes than for the samples mixed and kept at $4{ }^{\circ} \mathrm{C}$.

When we compare the solubility diagrams for these systems under different conditions $(100 \mathrm{mM} \mathrm{NaBr}$ and
$T=25{ }^{\circ} \mathrm{C}$ vs $0.01 \mathrm{mM} \mathrm{NaBr}$ and $T=4{ }^{\circ} \mathrm{C}$ ), both corresponding to dsDNA systems, we see that the two precipitation lines coincide, except for the most dilute part (Figure 5c). These low concentrations of DNA are reported to be the most "sensitive" regime to parameter changes in other related systems. ${ }^{36,37}$

The results clearly demonstrate major differences in the interactions with cationic surfactants between the two conformational states of DNA; these differences also have a bearing on our understanding of polyelectrolyte-surfactant interactions in general. From previous studies, both experimental and theoretical, on polyelectrolyte-surfactant systems, we know that the linear charge density of the polyelectrolyte, its flexibility, and any amphiphilic character will play a significant role. ${ }^{38-41}$ We note that the linear charge density of dsDNA $(\sim 0.59$ negative charges $/ \AA)$ is considerably higher than for ssDNA $(\sim 0.29$ negative charges/Å), and from a simple electrostatic mechanism, dsDNA should interact more strongly with oppositely charged polyelectrolytes or surfactant micelles.

Regarding chain flexibility, ssDNA has a much higher flexibility than dsDNA, which is quite rigid and characterized by a large persistence length $\left(\sim 500 \AA^{42,43}\right)$. In simulations, the role of flexibility of the polyelectrolyte has been documented in some detail, and it was found that a flexible chain in general interacts more strongly with an oppositely charged macroion ${ }^{44}$ than a rigid one.

When a polyelectrolyte contains some hydrophobic groups, the association of oppositely charged surfactants is much strengthened because of the combination of electrostatic and hydrophobic attraction. DNA is, because of the bases, an amphiphilic polyelectrolyte. The hydrophobic interaction between the bases drives the association of the two DNA chains into the double helix. Clearly, the amphiphilic character is very different for the DNA states: in dsDNA, the hydrophobic groups are largely hidden, whereas they are exposed to the solution for ssDNA. We expect then that in the latter case hydrophobic interactions would be much more significant.

These arguments also have consequences for the variation of the DNA-cationic surfactant interactions with surfactant alkyl chain length, but the variation should be different for surfactants that form micelles under the experimental conditions and those which do not. Studies on DNA melting in the presence of alkyltrimethylammonium bromide salts have been done, ${ }^{35,45}$ it was shown that the melting temperature decreased with increasing chain length in a linear fashion up to pentyl substitution ${ }^{35,45}$ (non micelle forming surfactants), whereas in the presence of CTAB (a readily micelle forming surfactant), the melting temperature increases ${ }^{46}$ (and increases the rate of nucleic acid renaturation ${ }^{47}$ ). It is our belief that a micelle-forming surfactant should associate with DNA mainly by electrostatic interactions and both charge densities and DNA flexibility will have important influence. For a surfactant that does not form micelles, electrostatic interactions are expected to be rather insignificant, whereas hydrophobic interactions should be important. It can be argued that the behavior of micelle forming surfactants will be different in the pre- and post-micellar region; however, 


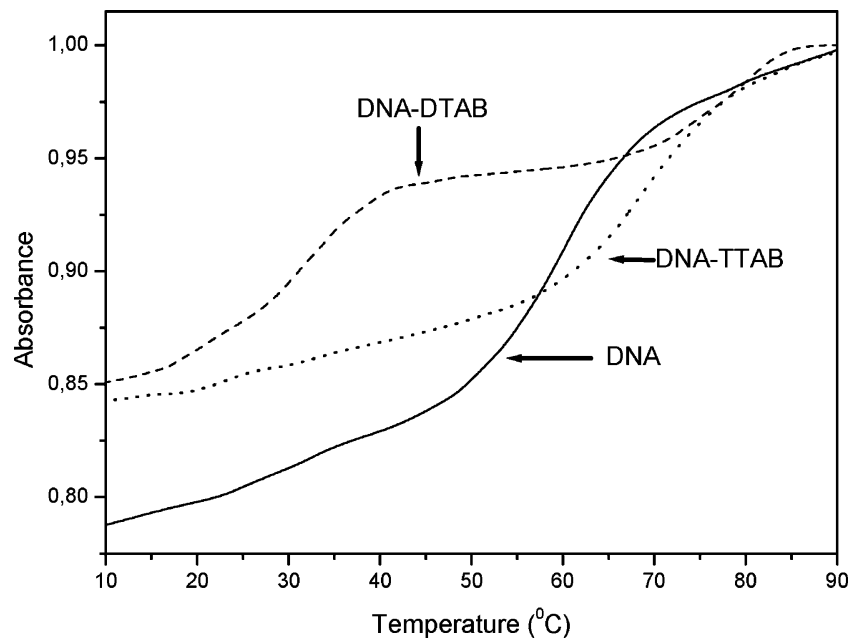

Figure 6. Melting curves of DNA, $0.1 \mathrm{mM}$ (solid line), $0.1 \mathrm{mM}$ DNA-1.5 mM DTAB (dashed line), and 0.1 mM DNA-0.15 mM TTAB (dotted line).

since the CAC is much lower than the surfactant critical micellar concentrations (CMC), it is our belief that the interactions between DNA and surfactant monomers are not significant.

Regarding the variation with surfactant alkyl chain length, the interaction can be predicted to be different for ss- and dsDNA. For the hydrophobic interaction, the association of nonmicellar surfactant should be significant for ssDNA and should increase with alkyl chain length, whereas it is expected to be insignificant for dsDNA.

Micellar surfactants associate to both conformational states of DNA. Micellar size and thus both the total charge of the micelles and their charge density increases with surfactant alkyl chain length. For two reasons, the association will become more favorable for dsDNA as compared to ssDNA as the surfactant alkyl length increases. First, the higher charge density of the micelles leads to a stronger interaction with the conformation with higher linear charge density. Second, since the micelle curvature decreases with micelle size, the higher rigidity of dsDNA will become less significant. Results obtained earlier in our group fit well to these arguments since we observed differences between the system with and without salt for DTAB (the shorter chain surfactant used), TTAB and CTAB (the longer chain surfactant used), the latter binding preferentially to dsDNA (Figure 4 from ref 21). Chatterjee et al. also showed that the free energy of binding between DNA and a cationic surfactant decreases with an increase of the surfactant alkyl chain, when going from DTAB to CTAB. ${ }^{48}$

These arguments lead to some important predictions regarding the relative stabilities of the two conformational states of DNA. First, for short-chain cationic amphiphiles, the melting point is predicted to decrease with chain length because of the stabilization of ssDNA. Second, for longchain surfactants, the melting point is expected to increase with chain length because of the stabilization of dsDNA. This was in fact demonstrated and can be seen in Figure 6, where the melting temperature curve shows that in the presence of DTAB, a 12 carbon chain surfactant, the DNA melting temperature decreases substantially compared to

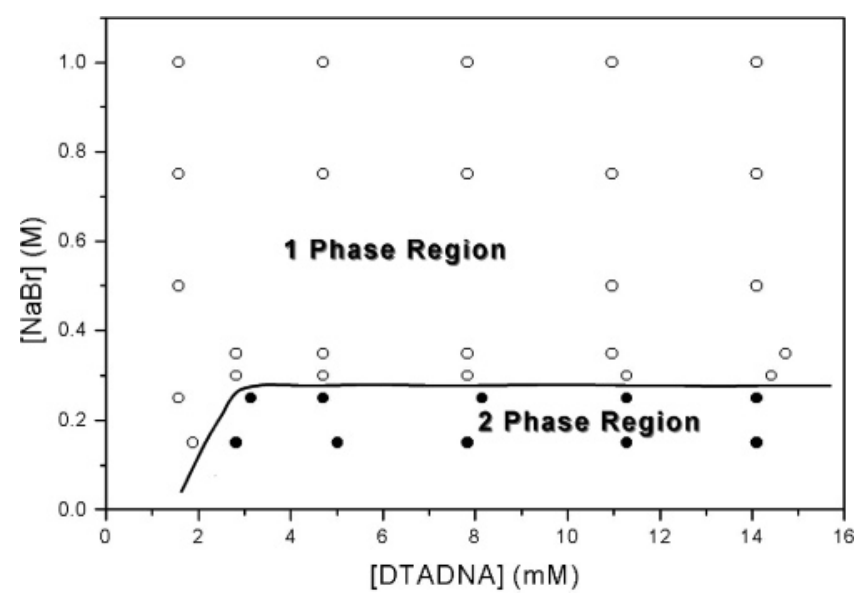

Figure 7. Dissolution of the DTA-DNA complex with simple salt, $\mathrm{NaBr}$. The solid symbol corresponds to two-phase samples and the open symbols correspond to clear solutions. $T=25^{\circ} \mathrm{C}$.

DNA alone, whereas for TTAB, a 14 carbon chain surfactant, the melting temperature increases.

The addition of simple salt to these polyelectrolyteoppositely charged surfactant systems has, in general, large consequences. ${ }^{21,35}$ The screening of the electrostatic attractions between the oppositely charged components leads to an increase in CAC. This can reduce strongly the phase separation, and, at high enough concentrations of salt, even eliminate it, and a total miscibility regime can be achieved. ${ }^{49}$ Precipitation studies were also performed on the DTA-DNA complex free of counterions at increasing salt concentrations; we tried to determine the boundary of the miscibility regime, see Figure 7. This phase boundary represents the so-called critical electrolyte concentration, CEC, which by definition is the concentration of salt needed for redissolution of the complex to occur. The concept of a critical electrolyte concentration was first introduced by Scott. ${ }^{50,51}$ From Figure 7 , it is possible to infer that for a complex concentration up to $1.9 \mathrm{mM}$ we have miscibility just by adding as little as $150 \mathrm{mM}$ of $\mathrm{NaBr}$. From this point on, the curve rises steeply from the onset of phase separation up to a maximum, where a plateau is reached. Above $300 \mathrm{mM}$ of salt the complex redissolves for all complex concentrations studied, and it becomes independent of DNA-surfactant concentration. This behavior seems to be a common feature of these systems. ${ }^{52,53}$ The decrease of the two phase region has as well been observed in other polyelectrolyte-oppositely charged surfactant systems. ${ }^{49,52,53}$ It can be explained by the fact that the entropy gain in the counterion release in the association of the oppositely charged species is highly reduced on addition of relatively high amounts of salt. ${ }^{54}$

In the phase diagram of DNA with DTAB at different salt concentrations, we found that the two DNA conformational states show different phase behavior, which relates, respectively, to a difference in the interaction between ssDNA and dsDNA with DTAB. These facts also bring interesting perspectives from an application point of view, namely the possibility of easily separating dsDNA from ssDNA by a controlled addition of surfactant. We proved this by performing the following study: we started with a mixture of $0.87 \mathrm{mM}$ of thermally denaturated ssDNA and $0.55 \mathrm{mM}$ of dsDNA. Then we added DTAB to the final concentrations 


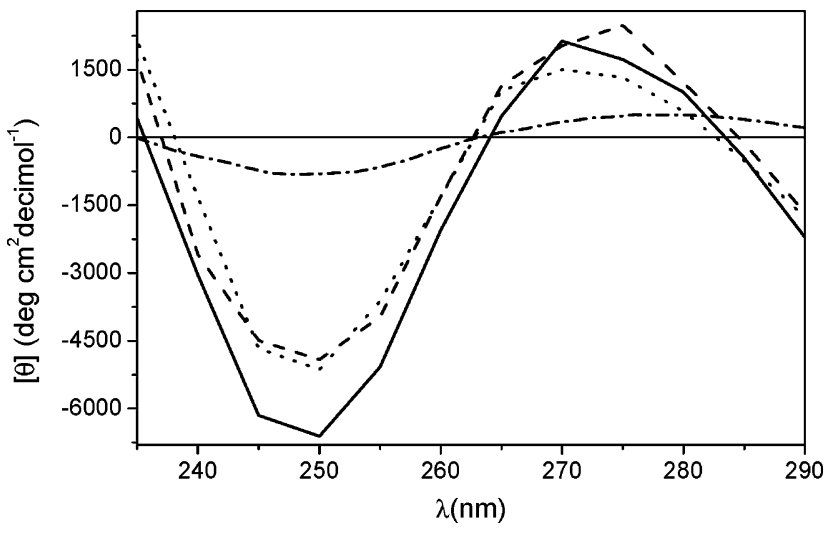

Figure 8. $C D$ measurements of the supernatant when mixing $0.55 \mathrm{mM}$ dsDNA and $0.87 \mathrm{mM}$ ssDNA with DTAB at different final concentrations: 1.2 (dashed line), 1.6 (dotted line), and $3 \mathrm{mM}$ (dashdotted line). The solid line corresponds to the mixture of $0.55 \mathrm{mM}$ dsDNA and $0.87 \mathrm{mM}$ ssDNA without surfactant. All results are normalized for DNA concentration. $T=25^{\circ} \mathrm{C}$.

of $1.2,1.6$, and $3 \mathrm{mM}$. The samples were left to equilibrate for $24 \mathrm{~h}$. Afterwards, a suitable amount of the supernatant was carefully pipetted and its CD spectra recorded. Results are presented in Figure 8. The solid line represents the initial mixture of ss and dsDNA. When we start adding surfactant, we observe that the negative band decreases in amplitude while the positive band keeps more or less constant. We also see that these two spectra suffered a small red shift at the crossover point when compared with the spectrum of dsDNA, presented in Figure 1 and described above. These are common characteristics of CD spectra of DNA with cationic surfactants. ${ }^{25,28-30}$ However, when we added DTAB to the final concentration of $3 \mathrm{mM}$, we obtained a CD spectrum representative of a solution of dsDNA alone, which means that all ssDNA has precipitated with DTAB and only dsDNA molecules were now present in solution. Further work is being conducted to improve the separation technique; the possibility of separating native DNA from denaturated one, by precipitation with short-chain surfactants, based on knowledge of the phase behavior appears novel and promising for the separation and purification of nucleic acids.

\section{Conclusions}

When studying the stability of the double-helix DNA molecules in solution by means of $\mathrm{CD}$, UV absorption, and DSC, we found that for dilute solutions of DNA with no addition of salt the DNA molecules are in the single-stranded conformation, whereas the addition of a small amount of $\mathrm{NaBr}, 1 \mathrm{mM}$, is sufficient to stabilize the double-helix DNA. Furthermore, we found that as little as $0.56 \mathrm{mM}$ of DNA in solution, without addition of salt, was enough to start stabilizing dsDNA, so we can, in principle, conclude that beyond this value in DNA concentration no addition of salt is necessary to stabilize the secondary structure.

The DNA-DTAB aqueous system shows a strong associative behavior with a large tendency to phase separate even for low surfactant and DNA concentrations. Redissolution of the precipitate was not achieved by adding an excess of surfactant, probably due to the formation of a stoichiometric complex and no additional binding of DTAB to it. However, addition of salt induces redissolution of the complex.

We also studied the phase behavior of ssDNA with DTAB, by monitoring the effect on the system of salt concentration and temperature. We found that ssDNA molecules precipitate for lower concentrations of surfactant than the double helix DNA molecules. This behavior is a promising tool from an application viewpoint, since we were able to separate dsDNA from ssDNA by precipitating the ssDNA molecules first, through the addition of DTAB. The knowledge that we can induce the DNA release from the DNA-cationic surfactant complexes by the addition of a large amount of salt or by the addition of anionic surfactant ${ }^{55,56}$ allows for the recovering of the precipitated material.

The difference in association between ss- and dsDNA with surfactants of different chain lengths has also been discussed and can be interpreted in terms of an interplay between hydrophobic and electrostatic interactions, the latter being influenced by polymer flexibility. In this way, a nonmonotonic variation can be rationalized.

Acknowledgment. This work was supported by grants from the Fundação para a Ciência e Tecnologia (FCT, projects POCTI/QUI/45344/2002 and SFRH/BD/8357/2002), the Swedish Research Council (VR) and a grant from a EU Research Training Network, CIPSNAC (Contract No. MRTNCT-2003-504932)

\section{References and Notes}

(1) Horn, P. J.; Peterson, C. L. Science 2002, 297, 1824-1827.

(2) Nelson, D. L.; Cox, M. M. Lenhinger Principles of Biochemistry, 3rd ed.; Wroth Publishers: New York, 2000.

(3) Stryer, L. Biochemistry, 4th ed.; W. H. Freeman \& Company: New York, 1995.

(4) Wagner, E.; Cotten, M.; Foisner, R.; Birnstiel, M. L. Proc. Natl. Acad. Sci. U.S.A. 1991, 88, 4255-4259.

(5) Ogris, M.; Steinlein, P.; Kursa, M.; Mechtler, K.; Kircheis, R. Wagner, E. Gene Therapy 1998, 5, 1425-1433.

(6) Kimura, T.; Yamaoka, T.; Iwase, R.; Murakami, A. Macromol. Biosci. 2002, 2, 437-446

(7) Yoshikawa, K. Adv. Drug Delivery Rev. 2001, 52, 235-244.

(8) Koping-Hoggard, M.; Mel'nikova, Y. S.; Varum, K. M.; Lindman, B.; Artursson, P. J. Gene. Med. 2003, 5, 130-141.

(9) Lasic, D. Liposomes in Gene Delivery; CRC Press: Boca Raton, FL, 1997.

(10) Pinnaduwage, P.; Schmitt, L.; Huang, L. Biochim. Biophys. Acta 1989 , 985, 33-37.

(11) Rouzina, I.; Bloomfield, V. A. Biophys. J. 1999, 77, 3242-3251.

(12) Korolev, N. I.; Vlasov, A. P.; Kuznetsov, I. A. Biopolymers 1994, 34, 1275-1290.

(13) Cantor, C. R.; Schimel, P. R. Biophysical Chemistry III: the behavior of biological macromolecules; W. H. Freeman \& Company: New York, 1980.

(14) Thomas, R. Gene 1993, 135, 77-79.

(15) Trewavas, A. Anal. Biochem. 1967, 21, 324-\&.

(16) Sibatani, A. Anal. Biochem. 1970, 33, 279-\&.

(17) Delsal, G.; Manfioletti, G.; Schneider, C. Biotechniques 1989, 7, 514.

(18) Francino, O.; Pinol, J.; Cabre, O. J. Biochem. Biophys. Methods 1987, $14,177-180$.

(19) Ishaq, M.; Wolf, B.; Ritter, C. Biotechniques 1990, 9, 19-\&.

(20) McLoughlin, D. M.; O’Brien, J.; McManus, J. J.; Gorelov, A. V.; Dawson, K. A. Bioseparation 2000, 9, 307-313.

(21) Dias, R.; Mel'nikov, S.; Lindman, B.; Miguel, M. G. Langmuir 2000 , 16, 9577-9583.

(22) Sambrook, J.; Fritsch, E. F.; Maniatis, T. Molecular Cloning: $a$ laboratory manual; Cold Spring Harbor Labiratory Press: New York, 1989; Vol. 3, App. C.1.

(23) Saenger, W. Principles of Nuclei Structure; Springer-Verlag: New York, 1984. 
(24) Gray, D. M.; Ratliff, R. L.; Vaughan, M. R. Methods Enzymol. 1992, 211, 389-406.

(25) Spink, C. H.; Chaires, J. B. J. Am. Chem. Soc. 1997, 119, 1092010928.

(26) Guschlbauer, W.; Marck, C.; Thiele, D. Stuct. Aspects Biomol. 1981, $228-254$

(27) Hanlon, S.; Brudno, S.; Wu, T. T.; Wolf, B. Biochemistry 1975, 14, $1648-1660$.

(28) Braun, C. S.; Jas, G. S.; Choosakoonkriang, S.; Koe, G. S.; Smith, J. G.; Middaugh, C. R. Biophys. J. 2003, 84, 1114-1123.

(29) Zhou, Y.; Li, Y. Colloids Surfaces A, Physicochem. Eng. Aspects 2004, 233, 129-135.

(30) Zhang, Z.; Huang, W.; Wang, E.; Dong, S. Spectrochim. Acta Part A, Mol. Biomol. Spectrosc. 2003, 59, 255-263.

(31) Cantor, C. R.; Schimel, P. R. Biophysical Chemistry III: The Behavior of Biological Macromolecules; W. H. Freeman \& Company: New York, 1980; Chapter 22.

(32) Manning, G. S. Acc. Chem. Res. 1979, 12, 443-449.

(33) Evans, D. F.; Wennerstrom, H. The Colloidal Domain - Where Physics, Chemistry, Biology and Technology Meet, 2nd ed.; WileyVCH: New York, 1999; Vol. 7.

(34) Inman, R. B.; Jordan, D. O. Biochim. Biophys. Acta 1960, 42, 421426.

(35) Orosz, J. M.; Wetmur, J. G. Biopolymers 1977, 16, 1183-1199.

(36) Raspaud, E.; de la Cruz, M. O.; Sikorav, J. L.; Livolant, F. Biophys. J. 1998, 74, 381-393.

(37) Raspaud, E.; Chaperon, I.; Leforestier, A.; Livolant, F. Biophys. J. 1999, 77, 1547-1555.

(38) Wallin, T.; Linse, P. J. Phys. Chem. B 1997, 101, 5506-5513.

(39) Wallin, T.; Linse, P. J. Phys. Chem. 1996, 100, 17873-17880.
(40) Wallin, T.; Linse, P. Langmuir 1996, 12, 305-314.

(41) Kwak, J. C. T. Polymer-Surfactant Systems; Marcel Dekker: New York, 1998.

(42) Tinland, B.; Pluen, A.; Sturm, J.; Weill, G. Macromolecules 1997, 30, 5763-5765.

(43) Lu, Y.; Weers, B.; Stellwagen, N. C. Biopolymers 2002, 61, 261275.

(44) Jonsson, M.; Linse, P. J. Chem. Phys. 2001, 115, 10975-10985.

(45) Collins, J. M.; Rogers, K. S. Chem.-Biol. Interact. 1977, 19, 197203.

(46) Bhattacharya, S.; Mandal, S. S. Biochim. Biophys. Acta 1997, 1323, 29-44.

(47) Pontius, B. W.; Berg, P. Proc. Natl. Acad. Sci. U.S.A. 1991, 88, 8237-8241.

(48) Chatterjee, R.; Chattoraj, D. K. Biopolymers 1979, 18, 147-166.

(49) Lindman, B.; Thalberg, K. Interactions of Surfactants with Polymers and Proteins; CRC Press: Boca Raton, FL, 1993.

(50) Scott, J. E. Methods Biochem. Anal. 1960, 8, 146-196.

(51) Laurent, T. C.; Scott, J. E. Nature 1964, 202, 661-662.

(52) Thalberg, K.; Lindman, B. J. Phys. Chem. 1989, 93, 1478-1483.

(53) Thalberg, K.; Lindman, B.; Bergfeldt, K. Langmuir 1991, 7, 28932898.

(54) Thalberg, K.; Lindman, B.; Karlstrom, G. J. Phys. Chem. 1991, 95, 6004-6011.

(55) Bhattacharya, S.; Mandal, S. S. Biochemistry 1998, 37, 7764-7777.

(56) Dias, R. S.; Lindman, B.; Miguel, M. G. J. Phys. Chem. B 2002, 106, 12608-12612.

$\mathrm{BM} 050137 \mathrm{~N}$ 